Investigaciones Fenomenológicas, n. 8, 2011, 89-95.

e-ISSN: $1885-1088$

Traducir a Heidegger

\author{
Jesús Adrián Escudero \\ Universidad Autónoma de Barcelona, España \\ Jesus.adrian@uab.es
}

\begin{abstract}
Resumen: Últimamente se ha producido una copiosa traducción de textos de Heidegger. Ante la complejidad de sus expresiones, es necesario un trabajo de revisión y unificación de los términos castellanos. Con el ánimo de abrir un proceso de diálogo entre los traductores, expondremos brevemente algunos puntos en los que se ejemplifica el problema. Por un lado, se trata de mostrar las tareas de traducción todavía pendientes de Ser y tiempo, a pesar de las dos traducciones existentes. A tal efecto se realizan una serie de calas de pasajes, tanto de la versión de Gaos como de la de Rive$\mathrm{ra}$, ofreciendo en cada caso las propias sugerencias de traducción. $Y$, por otro lado, se expone a discusión un elenco de términos que todavía están pendientes de una traducción definitiva.
\end{abstract}

Palabras clave: Traducción, interpretación, hermenéutica, Heidegger, Ser y Tiempo.

\begin{abstract}
In recent times, there has been a lot of translation of Heidegger's texts. The complexity of his philosophical expressions and the diversity of translation solutions offered so far need to be unified. In order to open a dialogue among translators we would like to expose briefly some examples that illustrate the problem of translation. On the one hand, we show that the task of translating Sein und Zeit is not yet finished, despite the translations of Gaos and Rivera. We take under consideration some quotes from Gaos's and Rivera's versions, offering in each case our own translation suggestion. On the other hand, we bring up for discussion different Heideggerian terms whose translations are still problematic.
\end{abstract}

Keywords: Translation, interpretation, hermeneutics, Heidegger, Being and Time.

Planteemos el problema de la peculiar situación de la filosofía española. Es cierto que la filosofía española ha tenido momentos de apogeo, quizás insuficientemente presentes en la memoria colectiva. Pero en lo que se refiere a la filosofía moderna y contemporánea hemos dependido más de la importación de filosofía que de su exportación, lo cual significa que todavía no hemos brillado por la producción masiva de pensamientos propios. Esto equivale a reconocer que necesitamos la traducción. Si la traducción es deficiente, pueden montarse falsas especulaciones, con apariencia de profundas, basadas en un texto desfigurado. Por ello nos parece oportuno plantear la pregunta de si la comunidad 
filosófica tiene suficiente conciencia de la necesidad de traducción y rinde suficiente gratitud a los que le prestan esta tarea.

En el caso de Heidegger el problema se agrava por la reflexión siguiente: diríamos que la traducción perfecta de Ser y tiempo es una empresa desesperada, ya que Heidegger creó su propio lenguaje, en muchos casos sin antecedentes históricos, y no ha habido ninguna interpretación de su terminología que merezca una fiabilidad especial. Por tanto, si él en parte creó una constelación conceptual que en muchos casos carece de precedentes y no confió a nadie la interpretación de la misma, ¿en qué situación se encuentra el traductor frente a las creaciones terminológicas de Heidegger? ¿Es posible alcanzar una traducción heideggeriana con plenas garantías? Probablemente, no. Incluso en el original mismo es imposible una lectura unívoca para el lector alemán. Cualquier literato alemán se encontrará desconcertado antes expresiones del tipo welten, nichten, zeitigen, Geviert, Jeweiligkeit o Gestell.

En este sentido, no resulta demasiado extraño que Adorno acusara a Heidegger de construir toda una jerga de la autenticidad. Ahora bien, más allá de este hecho, cabría preguntarse si Heidegger fue el único que atentó contra la lengua de Goethe o si bien puede hablarse de barroquismo académico en toda una generación de pensadores alemanes entre los que cabría incluir a Habermas y al mismo Adorno. ¿Se relaciona este estilo prenazi y postnazi con una situación que tiene tanto de búsqueda como de inseguridad y ocultación? En el contexto de estas observaciones el traductor podría tener una sensación de libertad, puesto que, al no estar atado por un claro sentido de la gramática al uso, le queda un amplio margen de configuración propia. Pero, por otra parte, si no intentamos adecuar al castellano todo un conjunto de conceptos básicos, corremos el peligro de dejar vía libre a la barbarie en el lenguaje filosófico.

Resulta obvio que toda referencia a la tarea de la traducción de textos de Heidegger tiene que pasar, en primer lugar, por su obra principal Ser y tiempo. En la actualidad contamos con dos traducciones de la obra comentada; a saber, la de Gaos (1951) y la de Rivera (1998). La de Gaos, al igual que otras traducciones extranjeras, está reclamando una revisión de su terminología y una actualización de su estilo. En este sentido, la primera versión italiana de Pietro Chiodi es objeto de revisión en la nueva traducción que está preparando Alfredo 
Marini ${ }^{1}$. Otro tanto puede decirse de las dos traducciones inglesas de Macquarrie \& Robinson (1962) y Joan Stambaugh (1996), que, además de generar un amplio debate en torno a la posibilidad de traducir Ser y tiempo, han planteado cuestiones relativas a la sintaxis, al barroquismo de algunas soluciones terminológicas, a la localización de diferentes omisiones y a la detección de errores de traducción ${ }^{2}$. Parece, pues, que la cuestión de la traducción de esta obra no está ni mucho menos resuelta. A este respecto resulta cuando menos llamativo el hecho de que en la actualidad existan siete versiones japonesas de Ser $y$ tiempo.

Centrándonos en nuestra lengua, la mayoría de nosotros hemos usado el texto de Gaos. Desde la perspectiva de medio siglo, podríamos vernos impulsados a censurar algunas de sus creaciones terminológicas como deformaciones monstruosas del castellano. Sin embargo, el traductor que esto escribe merece nuestro mayor respeto, pues tuvo que crear toda una terminología de nueva planta, en un momento en que no podía disponer de las lecciones del joven Heidegger. Estas lecciones son un material documental que en la actualidad permite una reconstrucción bastante fidedigna de la génesis de Ser y tiempo y de sus términos fundamentales ${ }^{3}$. En este sentido, la abundante literatura secundaria sobre la obra temprana de Heidegger destaca la impronta teológica y la herencia fenomenológica, así como el cuño aristotélico y la filiación hermenéutica de buena parte de su arsenal conceptual. Pero, más allá de la simple colección de afinidades, hay que insistir en la importancia que ya el joven Heidegger concede a la cuestión metodológica de la formación de conceptos; una cuestión que se pone especialmente de manifiesto en las audaces reformulaciones de términos griegos que encontramos en el Informe Natorp (1922). Aquí está en marcha todo un proceso de desmontaje crítico de conceptos transmitidos por la tradición filosófica, como, por ejemplo, los de alétheia, phrónesis, ousía o téchne. Heidegger (que reconoce que en la usual interpretación hereda-

\footnotetext{
${ }^{1}$ Cfr., por ejemplo, el artículo de Alfredo Marini y Riccardo Lazzari "Traduttori e traduzioni de Sein und Zeit", Maggazino di Filosofia, número monográfico Tradurre Essere i tempo, 2 (2000) 17-29, así como las sugestivas consideraciones de Franco Volpi, editor de numerosas traducciones italianas de Heidegger, realizadas en una entrevista publicada por la revista Chora (2001) 24-27.

${ }_{2}$ Cfr. el crudo diagnóstico de Thomas Sheehan acerca de las lagunas de la traducción de Joan Stambaugh en "Let a Hundred Translations Bloom! A Modest Proposal About Being and Time", Man and World 30 (1997) 227-238.

${ }^{3} \mathrm{~A}$ este respecto, resulta muy ilustrativo el glosario de conceptos fundamentales elaborado por Theodore Kisiel en The Genesis of Heidegger's Being and Time, Berkeley / Los Angeles, University of California Press, 1993, pp. 409-513.
} 
da existen elementos que pueden ocultar, desfigurar, encubrir, velar, deformar, enmascarar, nivelar o desvirtuar nuestra comprensión inmediata de la situación hermenéutica) desarrolla una estrategia de destrucción que retrotraiga los conceptos a su sentido originario, que los comprende desde la experiencia inmediata de la que surgieron ${ }^{4}$. Esta desconfianza frente a la tradición metafísica y esta sensibilidad etimológica se agudizan luego en el segundo Heidegger. Por ejemplo, "ereignen" y "Ereignis" en muchos contextos sólo tiene sentido si recurrimos al significado etimológico. Éste es el caso concreto que encontramos en la conferencia Tiempo y ser. En ¿Qué significa pensar? "vorläufig" se usa en el sentido de "precursar" y sería un disparate traducirlo por "transitorio". En este último texto, Heidegger deriva el sentido de "be-wahren" (conservar) y "währen" (durar) a partir del antiguo alemán "die Wahr", que se mantiene todavía en la palabra castellana "guarda"5.

Por lo que refiere a Ser y tiempo, sin menoscabo de nuestro reconocimiento de los esfuerzos de Gaos, creemos sinceramente que su texto no puede ser definitivo. La traducción de Rivera, a tenor de las prospecciones que hemos realizado, ha mejorado sobre todo en fluidez, pero todavía deja que desear en muchos puntos. Por no marearles en el vals del traductor nos limitamos a un par de ejemplos. En el parágrafo 18 de Ser $y$ tiempo leemos:

Bewandtnis ist das Sein des innerweltlichen Seienden, darauf es je schon zunächst freigegeben ist. Mit ihm als Seindem hat es je eine Bewandtnis. Dieses, dass es eine Bewandtnis mit... hat, ist die ontologische Bestimmung des Sein des Seienden [...]. ${ }^{6}$

\section{Gaos traduce:}

La conformidad es el ser de los entes intramundanos sobre la base del cual se les da libertad en cada caso ya inmediatamente. Con ellos como entes se guarda en cada caso conformidad. Este 'guardar conformidad' es la determinación ontológica del ser de estos entes $[\ldots . .]^{7}$

En cambio, Rivera dice:

\footnotetext{
${ }^{4} \mathrm{Cfr}$. Martin Heidegger, Interpretaciones fenomenológicas sobre Aristóteles. Indicación de la situación hermenéutica (edición y traducción de Jesús Adrián), Trotta, Madrid, 2002, pp. 52s. Una planteamiento que está en perfecta sintonía con el programa de destrucción esbozado en Ser y tiempo (§ 6) y en Los conceptos fundamentales de la fenomenología (\$ 5).

${ }^{5}$ Cfr. Diccionario de la Real Academia, Madrid, Espasa-Calpe, $1992^{21}$, p. 753.

${ }^{6}$ Martin Heidegger, Sein und Zeit, Tubinga, Max Niemeyer, $1986^{16}$, p. 84.

7 Martin Heidegger, El ser y el tiempo, México, Fondo de Cultura Económica, $1974^{5}$, p. 98. Traducción de José Gaos.
} 
Condición respectiva es el ser del ente intramundano; ser con vistas al cual en cada caso este ente queda puesto primeramente en libertad. Como ente, él tiene siempre una condición respectiva. Esto: que con él pasa que queda vuelto en condición respectiva hacia... es la determinación ontológica del ser de este ente $[\ldots]{ }^{8}$

Sin ninguna pretensión de brillantez vamos a intentar una traducción comprensible:

La conformidad es el ser de los entes intramundanos. En cada caso éstos han salido previamente a la luz en el horizonte de la conformidad. Dicho ser tiene siempre una conformidad con ellos en cuanto son entes. Este hecho, el de que guarda una conformidad, es la determinación ontológica del ser de estos entes [...].

Un último ejemplo elegido al azar. El texto original reza como sigue:

Damit bezeichnen wir das in der eigentlichen Entschlossenheit liegende ursprüngliche Geschehen des Daseins, in dem er sich frei für den Tod ihm selbst in einer ererbten, aber gleichwohl gewählten Möglichkkeit überliefert. ${ }^{9}$

La traducción de Gaos de este pasaje es:

Con esta expresión designamos el gestarse original del 'ser-ahí', gestarse implícito en el 'estado de resuelto' propio y en que el 'ser-ahí' se hace tradición de sí mismo, libre para la muerte, a sí mismo, en una posibilidad heredada pero, sin embargo, elegida. ${ }^{10}$

\section{Rivera ofrece la siguiente versión:}

Con esta palabra designamos el acontecer originario en el que el Dasein que tiene lugar en la resolución propia, acontecer en el que el Dasein, libre para la muerte, hace entrega de sí mismo a sí mismo en una posibilidad que ha heredado, pero que también ha elegido. ${ }^{11}$

\section{Y nuestra propuesta sería:}

Con ello designamos el acontecer originario del Dasein que subyace en la resolución propia, un acontecer en el que el Dasein se entrega libremente a la muerte en un posibilidad heredada y, a la vez, elegida.

Es obvio que muchas tareas están todavía por resolver. La primera es la traducción de Dasein, ya que en esta palabra se condensa el significado de la obra. "Ser-ahí" es un término muy aceptable en sentido literal, pero no indica el

\footnotetext{
${ }^{8}$ Martin Heidegger, Ser y tiempo, Santiago de Chile, Editorial Universitaria, 1998, p. 110. Traducción de Jorge Eduardo Rivera.

${ }_{9}^{9}$ Martin Heidegger, Sein und Zeit, Tubinga, Max Niemeyer, $1986^{16}$, p. 384.

${ }_{10}$ Martin Heidegger, El ser y el tiempo, México, Fondo de Cultura Económica, $1974^{5}$, p. 414. Traducción de José Gaos.

${ }^{11}$ Martin Heidegger, Ser y tiempo, Santiago de Chile, Editorial Universitaria, 1998, p. 400. Traducción de Jorge Eduardo Rivera.
} 
contenido al que apunta el autor. El sentido del término está estrechamente vinculado con los conceptos de "propiedad" (Eigentlichkeit) e "impropiedad" (Uneigentlichkeit), usados en traducciones como El concepto de tiempo o el Informe Natorp, en contraposición a los que optan por "autenticidad" e "inautencidad"12. A diferencia de Gaos, Rivera deja el término en alemán, lo cual no resuelve el problema. Algunos abusan de esta alternativa. También parecía que "Gestell" no admitía traducción hasta que el traductor de la biografía de Safranski introdujo la palabra "engranaje", que no es inmune a la discusión, pero goza de una cierta acogida como se deduce por el número de Babelia del día 12 de enero de 2002.

Nosotros nos resistimos a la introducción de términos extranjeros. Y en el caso concreto de Heidegger, si fuéramos excesivamente tolerantes frente a esta tendencia, nos encontraríamos con unos textos plagados de neologismos como Lichtung, Weltanschauung, Ereignis, Gestell o Kehre. Admitida la posibilidad de dejar a veces el término entre paréntesis, por más que parece preferible añadir un índice de equivalencias al final, creemos que hay que exprimir los propios recursos lingüísticos. Y esto debe extenderse a los contextos en los que Heidegger está jugando con etimologías alemanas. En la primera traducción castellana de ¿Qué significa pensar? encontramos la siguiente redacción:

Pero nosotros tratamos ahora de destacar por lo menos algunos rasgos fundamentales del presenciar de lo presente. Sirva de ejemplo una cordillera que se extiende ante nosotros. Si decimos a-sistir, an-wesen, entonces entendemos la palabra 'wesen' verbalmente y no como substantivo. Usado en este último sentido y escrito en mayúscula, 'Anwesen' nombra algo presente, a saber, una propiedad rural con sus bienes inmuebles. También la cordillera es un inmueble sui generis. La palabra alemana 'wesen' usada verbalmente es el 'wesan' del alto alemán antiguo. Es la misma palabra como 'währen' (durar) y significa: permanecer. 'Wesan' por su parte pertenece a la raíz de 'vásati' del idioma índico antiguo y significa: habita, permanece. Lo habitado se dice

12 Cfr. Martin Heidegger, El concepto de tiempo, Madrid, Trotta, 1999, p. 41 (prólogo, traducción y notas de Raúl Gabás y Jesús Adrián). Y, por otro lado, como hemos apuntado en las notas aclaratorias de la traducción del Informe Natorp hay que prestar atención a la raíz alemán eigen, que significa "propio", "peculiar", "característico" o "especial". Un sentido, según el diccionario de los hermanos Grimm, que remite a los términos griego idios y al latín proprius; unos términos que, a su vez, están estrechamente emparentados con ejein y habere, esto es, "apoderarse", "retener", "lo que le pertenece a uno" o "lo que depende de uno mismo". Eigen, a tenor de las observaciones de los hermanos Grimm, también remite a la idea de "seguir el propio camino guiándose por el espíritu" o "estar en casa y a cobijo de las inclemencias". Nos hallamos ante diferentes giros que, de una u otra manera, aluden a la existencia de un esfera privada, interior, genuina, secreta, originaria o extraordinaria que no se ve afectada por los acontecimientos externos. Esto significa en términos heideggerianos que el ser humano es un ente que tiene la difícil tarea de empuñar su propia existencia como algo que le pertenece en propiedad (Eigentum), de tomar posesión de la existencia en cada caso mía (jemeinig). 
(en alemán) el 'Hauswesen' (lo doméstico). El verbo 'wesan' significa: estancia permanente. ${ }^{13}$

He ahí nuestra propuesta de traducción:

No todo lo que de alguna manera es se hace presente en igual manera. Con todo, intentaremos ahora resaltar por lo menos algunos rasgos de la presencia de lo que se hace presente. Tomemos como ejemplo una montaña que está ante nosotros. Si decimos presentarse, entendemos la palabra como verbo y no como substantivo. La palabra en forma de substantivo puede significar, por ejemplo, el aspecto que una persona tiene. También la montaña tiene su presencia. El verbo alemán wesen es lo mismo que el antiguo alto alemán wesan; es la misma palabra que währen y significa: permanecer. Wesan pertenece a la raíz vásati del antiguo idioma indio, con el sentido de él habita, él se demora. Lo habitado se llama estancia. La palabra temporal wesan significa: demorarase establemente.

Nuestras reflexiones se refieren a los problemas de traducción de Heidegger y se podrían extender a la traducción en general. En el caso paradigmático del autor comentado, queremos resaltar la necesidad de un encuentro entre personas interesadas en las tareas de la traducción con el fin de elaborar una terminología en la que realmente se logre establecer una base común de diálogo para no obligar a Cervantes a salir de su sepulcro y a poner orden entre nosotros -escritor, por cierto, que formuló muy a la española la posterior relación hegeliana entre el siervo y el señor.

${ }^{13}$ M. Heidegger, ¿Qué significa pensar?, Buenos Aires, Editorial Nova, 1958, p. 226. Traducción de Haraldo Kahnemann. 